\title{
Preventing moral catastrophes in modern health care systems by facilitating the development of a Socratic ethos: a big idea from an Arendtian perspective
}

Roberts M., Ion R.

NOTICE: this is the author's version of a work that was accepted for publication in Nurse Education Today. Changes resulting from the publishing process, such as peer review, editing, corrections, structural formatting, and other quality control mechanisms may not be reflected in this document. Changes may have been made to this work since it was submitted for publication. A definitive version was subsequently published in Nurse Education Today, Vol. 34, issue 12, (2012). DOI: http://dx.doi.org/10.1016/j.nedt.2014.08.010 
Preventing moral catastrophes in modern health care systems by

facilitating the development of a Socratic ethos: a big idea from an

Arendtian perspective

\section{Authors}

Roberts M, Abertay University, Division of Nursing and Counselling

Ion R, Abertay University, Division of Nursing and Counselling

Division of Nursing and Counselling, School of Social and Health Sciences, Abertay University, Dundee

Address for correspondence: Robin Ion, Division of Nursing and Counselling, School of

Social and Health Sciences, Abertay University, Dundee. Email r.ion@abertay.ac.uk 


\section{Introduction}

In a recent paper the authors proposed that the work of Hannah Arendt could be employed to provide a productive understanding of how it is that systemic 'moral catastrophes' can occur in modern health care systems (Roberts \& Ion, 2014). From an Arendtian perspective the widespread participation of practitioners in those catastrophes such as that typified by the events at Mid Staffordshire NHS Trust (see, e.g. Francis, 2013) - cannot coherently be understood by invoking notions of 'inherent evil' or 'wickedness' but should rather to be understood as a consequence of an 'authentic inability to think' or 'thoughtlessness' (Arendt, 1992; p. 288). In particular, Arendt's work suggests that in so far as modern health care systems are increasingly characterised by instrumental rationality - a rationality that necessitates practitioners exercise their technical skills in accordance with institutional rules, policies and procedures and do so in a manner that seeks to continually maximise efficiency - then those practitioners become progressively habituated to thoughltlessness, habituated to the unreflective employment of the most efficient means to a given end without considered reflection on the moral appropriateness of the means employed or the ends pursued. As a response to such thoughtlessness, Arendt (1971) posits the need for what she refers to simply as 'thinking' and presents a characterisation of the ancient Greek philosopher Socrates as an exemplary instantiation of that thinking which can serve as a corrective to the thoughtlessness that is associated with instrumental, rule-governed rationality (p. 427). Accordingly, this paper will seek to elucidate Arendt's account of Socrates in order to begin to develop the implications of that characterisation for the providers of health care education. In particular, it will suggest that the development of what can be referred to as a 'Socratic ethos' in health care students may challenge the thoughtlessness that is associated with instrumental rationality and prevent the widespread thoughtless participation of health care practitioners in systemic moral catastrophes. 


\section{Arendt's Socrates}

In seeking to employ Socrates as instantiation of a thinking that can disrupt thoughtlessness - and while noting the scholarly difficulties in assigning a representative function to an historical figure (Arendt, 1971, p. 427) - Arendt presents a characterisation of Socrates in Thinking and Moral Considerations that is congruent with that presented by Plato (1961a) in The Apology. On trial and defending himself against the charge of 'corrupting the minds of the young, and of believing in deities of his own invention instead of the gods recognized by the state', Socrates is presented as giving a detailed account of the philosophical activity upon which he has been engaged throughout Athens and which has led to him incurring the widespread resentment of Athenian 'professional men and politicians' (Plato, 1961a; p. 10). In elucidating the nature of this philosophical activity - that Socratic, reflective rationality or thinking that is presented as challenging the thoughtlessness that is associated with instrumental, rule-governed rationality Arendt (1971) notes that the characteristic methodological approach that Socrates employed involved calling into question those seemingly simple words or concepts that are part of our everyday speech, words such as 'happiness, courage, justice, etc.' and which become elusive and 'slippery' when we try and define them (p. 429). In particular, Socrates was concerned with questioning those Athenians who had a 'high reputation for wisdom' to see if they could provide a coherent account of what they meant when they employed those everyday terms and, through such questioning, to examine if their high reputation for wisdom was warranted (Plato, 1961a; p. 7). In doing so, however, Socrates suggests that he not only discovered that the high reputation of the professional men and politicians of Athens was unwarranted, not only were they unable to provide coherent accounts of what they meant when they employed those everyday terms, but their lack of wisdom was compounded in so far as they believed that they possessed a level of wisdom that they manifestly did not (Plato, 1961a; pp. 7-8). 
In beginning to consider the implications of Arendt's employment of Socrates for the providers of health care education, however, it is important to note that the value of Socrates' thinking for Arendt does not rest on the specific content of that thinking that Plato's dialogues recount. Arendt ought not to be understood as choosing Socrates because of the particular everyday concepts that he called into question, such as happiness, courage and justice, and neither is the particular method of cross examination that Socrates employed, the elenchus, central to the manner in which Socrates' activity can serve as a model for disrupting the thoughtless, widespread participation in systemic moral catastrophes. Indeed, in seeking to continually question the knowledge and the wisdom of others, Socrates did not seek to assert his own wisdom by providing definitions of everyday concepts, nor did he seek to teach a method, a set of doctrines or a body of knowledge the truth of which he sought to convince others (see, e.g. Colaiaco, 2002; Johnson, 2012; Miller, 2012). As Arendt (1971) makes clear, 'Socrates, as he repeatedly said, did not teach anything for the simple reason that he had nothing to teach' (pp. 431-432). Moreover, within the context of the increasing predominance of instrumental rationality in modern health care systems - and, in particular, the demand for health care professionals to efficiently exercise their technical skills in accordance with specific sets of rules, procedures and protocols - the thinking, reflective questioning that Arendt (1971) presents as Socrates' philosophical activity is often understood as 'unproductive' and even 'entirely without results' (p. 431). For example, in highlighting the 'aporetic' character of this activity, the manner in which Plato's Socratic dialogues either 'lead nowhere' or go 'round in circles', Arendt (1971) proposes that 'thinking as such does society little good, much less than the thirst for knowledge in which it is used as an instrument for other purposes' such that, 'except in emergencies', the questioning that characterises Socratic reflective rationality must be understood as 'a marginal affair for society at large' (p. 445). 


\section{The Socratic Ethos}

Despite suggesting that Socrates 'had nothing to teach' and that his philosophical activity can be understood as 'aporetic', Arendt (1971) is clear that the activity upon which he was engaged continues to possess a contemporary significance, value and worth (pp. 445446). However, rather than evaluating that worth in terms of the specific content of Socrates' thought or the particular method of questioning that he employed, the value of Socrates for Arendt is to be understood as residing in the particular ethos that he instantiated. While an individual's ethos, understood in its ancient, Greek sense, incorporates that which manifests itself in a person's way of acting and responding to events, a way visible to others, it is not to be understood as being reducible to that way of acting or responding to events; rather, a person's ethos refers to their character and disposition towards things, an attitudinal stance towards the world or what might be referred to as a person's mode or way of being (Foucault, 2000; p. 286). The value of Socrates as a representative model is therefore to be understood as residing in the particular ethos that he instantiated, in his possession of an attitude or way of being that was disposed to question the seemingly self-evident 'truths' of everyday life, to call into question that which is regarded as 'common sense' and what 'everybody is supposed to know'. It is this Socratic ethos or disposition that maintains a contemporary significance for Arendt precisely because it has the ability to disrupt the habituated thoughtlessness that can be associated with the instrumental, rule-governed rationality that increasingly directs the everyday conduct of individuals within a given organisation or regime. In highlighting the ability of this ethos to disrupt the unreflective, rule-governed engagement in everyday activities, Arendt (1971) makes it clear that it manifests itself as 'the stop and think' such that this questioning ethos or disposition may produce 'a paralyzing effect' that entails you are 'no longer sure of what seemed to you beyond doubt while you were unthinkingly engaged in whatever you were doing' (p. 434). 
In considering the implications of Arendt's characterisation of Socrates for the providers of health care education, it is therefore important to note that the emphasis ought to be on facilitating the development of a Socratic ethos in health care students rather than attempting to duplicate the technical methods of questioning that he employed. The teaching of Socrates' method of questioning, or even more general skills of critical reflection, will be of limited value in seeking to challenge the thoughtless participation of health care practitioners in systemic moral catastrophes if those individuals do not possess the particular ethos that disposes them to employ those skills and question the seemingly unquestionable truths of the organisation within which they are situated. Rather, it is the development of an ethos or disposition to question that may challenge the thoughtlessness that can lead to systemic moral catastrophes in modern health care systems, a Socratic ethos that arises from an engaged suspicion towards all claims of what can be referred to as epistemological certitude, finality or closure, a suspicion towards any individual, professional body or organisation that effectively maintains that its knowledge base, procedures or protocols are, in theory or in practice, beyond question. Indeed, in accordance with much contemporary thought in the spheres of religion, politics, philosophy and science (see, e.g. Lyotard, 1997; Vattimo, 1999; Rorty, 2007; Kuhn, 2012), Arendt (1971) proposes that the long-standing, traditional intellectual pursuit of seeking to establish epistemological certitude, the variegated claims to have established, discerned or 'uncovered' truths that are effectively indubitable, has 'lost plausibility', 'fallen into disrepute' and 'come to an end' (pp. 419-421). The ethos that Arendt suggests Socrates instantiates is, in this respect, strikingly contemporary in so far as he maintained that he knew nothing of such epistemological certitude and that knowledge claims that were ostensibly unquestionable would have to be the reserve of a God, whereas the knowledge that human beings could possess would always be provisional, subject to revision and forever open to question (Plato, 1961a; p. 9). 


\section{Facilitating the development of a Socaratic ethos}

For health care professionals to 'stop and think', for health care professionals not to become progressively habituated to the unreflective employment of the most efficient means to a given end without considered reflection on the moral appropriateness of the means employed or the ends pursued, then it is necessary to facilitate the development of this Socratic ethos in health care students. However, in contrast to the teaching of technical skills and the assessment of their safe, effective and efficient performance, the facilitation of an ethos that instantiates an active suspicion towards claims of epistemological certitude, an ethos that disposes students to question that which is ostensibly unquestionable, presents a significant challenge to the providers of health care education. Indeed, in highlighting this difficulty, Arendt (1971) proposes that there is only one way that such a Socratic ethos can be taught, the only way in which she suggests that Socrates can be understood as having taught anything, and that is by presenting and sharing 'perplexities' with others (p. 431). That is, in order to facilitate the development of a reflective, questioning ethos or disposition, then it is necessary to present critical debates and issues to students, to seek to identify the uncertainties, controversies and perplexities that surround the theoretical foundations and clinical interventions that characterize contemporary health care. Moreover, the presenting and sharing of such perplexities, as Socrates himself made clear (Plato, 1961b; p. 363), does not entail presenting those perplexities from a position of expertise such that 'the educator' then reveals the supposed answer or solution that resolves the perplexity. Rather, congruent with the description of Socrates as a perplexed man who reduced others to perplexity (Plato, 1961b; p. 363), the facilitation of a disposition to question is made by an educator who is genuinely disposed to carry out a joint investigation into perplexities, valuing the contribution of students as co-inquisitors and, by doing so, creates a climate in which students feel empowered, validated and disposed to engage in reflective questioning. 
While facilitating the development of such a Socratic ethos involves creating a climate in which students feel empowered to question, those responsible for health care education also face the challenge of considering how to encourage students to exercise that disposition, and consider the consequences of exercising that disposition, in environments that are less receptive to such questioning. Indeed, Socrates' account at his trial of the manner in which his philosophical activity elicited bitter and persistent hostility from individuals, along with the judgment passed on him at the end of that trial by the professional men and politicians of Athens, vividly illustrates how individuals and organisations can react to the reflective, questioning ethos that he instantiated (Plato, 1961a; p. 9, p. 23). Similarly, Arendt (1971) highlights the manner in which the Athenians accused Socrates of being dangerously subversive and corrosive, and that the activity upon which he was engaged 'sweeps away all the established signs by which men orient themselves in the world; it brings disorder into the cities and it confuses the citizens, especially the young ones' (p. 436). To the extent that an individual, professional body or organisation has an interest in maintaining its authority and reputation for knowledge, and within the context of the increasing predominance of instrumental, rule-governed rationality in modern health care systems, then the questioning disposition that Socrates instantiated may be regarded as a distraction or annoyance at best and, at worst, as a dangerous and subversive challenge to the legitimacy and the efficient functioning of the organisation. To facilitate the development of a Socratic ethos in health care students, therefore, does not merely necessitate the development of an attitude of suspicion to claims of epistemological certitude, but also the development of the courage to actively engage that suspicion and ask questions of individuals, professional bodies and organisations who may have a multiplicity of historical, socio-political and institutional reasons to maintain the seemingly self-evident and unquestionable status of their knowledge base, procedures and protocols. 


\section{Conclusion}

Despite the challenges confronting those who would seek to facilitate the development of a Socratic ethos in health care students, Arendt's work is clear that such a disposition can serve as a corrective to the authentic inability to think or thoughtlessness that can be associated with the instrumental, rule-governed rationality that increasingly characterises modern health care organisations. Moreover, in contrast to the possession of technical, specialised health care skills and the increasingly efficient employment of those skills in accordance with organsiational rules, policies and produces, the development of that reflective, questioning disposition towards ostensibly self-evident truths that Arendt refers to simply as thinking is to be understood as a general attribute of all. As she makes clear: 'Thinking in the non-cognitive, non-specialized sense...is not a prerogative of the few but an everpresent faculty of everybody' (Arendt, 1971; p. 445). While modern health care systems require practitioners to possess and exercise technical skills in order to ensure the most effective and efficient means to a given end, the prevention of widespread, systemic participation in moral catastrophes also necessitates that they possess an ethos that disposes them, when necessary and in the face of individual, professional and organisational resistance, to actively call into question the moral appropriateness of the means being employed or the ends being pursued. Therefore, as an everpresent faculty or attribute of everybody that may disrupt thoughtless, unreflective and widespread participation in systemic moral catastrophes in health care, Arendt's work entails that the providers of health care education seriously consider how to facilitate the development and active engagement of a Socratic ethos in health care students, how this can be set alongside the educational demands of facilitating the acquisition of specialised knowledge and technical health care skills and, finally, how the two can coexist in health care systems that are increasingly characterised by instrumental, rule-governed rationality. 


\section{References}

Arendt, H., 1971. Thinking and moral considerations: a lecture. Soc. Res. 38, 417446.

Arendt, H., 1992. Eichmann in Jerusalem: A Report on the Banality of Evil. Penguin, New York.

Colaiaco, J.A., 2001. Socrates Against Athens: Philosophy on Trial. Routledge, New York.

Foucault, M., 2000. The ethics of the concern of the self as a practice of freedom. In: Rabinow, P. (Ed.), Ethics: Subjectivity and Truth. Penguin, London, pp. 281-301.

Francis, R., 2013. Report of the Mid Staffordshire NHS Foundation Trust Public Inquiry. Stationary Office, London.

Johnson, P., 2012. Socrates: A Man for our Times. Penguin, London.

Kuhn, T.S., 2012. The Structure of Scientific Revolutions. The University of Chigaco Press, Chicago.

Lyotard, J.F., 1997. The Postmodern Condition: A Report on Knowledge. Manchester University Press, Manchester.

Miller, J., 2012. The Philosophical Life. Oneworld Publications, Oxford. 
Plato, 1961a. The apology. In: Hamilton, E., Cairns, H. (Eds.), The Collected Dialogues of Plato. Princeton University Press, Princeton, pp. 3-26.

Plato, 1961b. The Meno. In: Hamilton, E., Cairns, H. (Eds.), The Collected Dialogues of Plato. Princeton University Press, Princeton, pp. 353-384.

Roberts, M., Ion, R., 2014. A critical consideration of systemic moral catastrophe in modern health care systems: a big idea from an Arendtian perspective, Nurse Educ. Today 34, 673-675.

Rorty, R., 2007. Contingency, Irony, and Solidarity. Cambridge University Press, Cambridge.

Vattimo, G., 1999. Belief. Blackwell, Oxford. 